\title{
Acción colectiva juvenil rural: resistencia y re-existencia en tiempos de posacuerdo (Riosucio, Colombia)
}

\author{
Rayén Amanda Rovira-Rubio, Ph.D. ${ }^{a}$ \\ Centro de Estudios Avanzados en Niñez y \\ Juventud, Colombia
}

María Antonia Montoya-Castaño, Mag. ${ }^{b}$

Joven investigadora Minciencias, Colombia

\section{Resumen (analítico)}

Este artículo recoge los hallazgos de una investigación sobre las prácticas de resistencia y re-existencia presentes en la acción colectiva juvenil desplegada en Riosucio (Caldas), zona rural afectada por el conflicto armado colombiano.Tuvo como objetivo analizar los modos en que la acción colectiva juvenil construye horizontes de paz en tiempos del posacuerdo. La investigación es cualitativa etnográfica e incorpora la etnografía visual; colaboraron cuatro colectivos juveniles con quienes además se elaboró una pieza fílmica documental. Como principales conclusiones se plantea: el surgimiento de los colectivos como apuesta a las violencias que reconocen en el territorio local y nacional, así como el potencial del arte como mecanismo de resistencia y re-existencia para la construcción de paz en lo rural, epicentro histórico de la guerra en la país.

\section{Palabras clave}

Joven rural, conflicto armado, violencia, resistencia, estética, paz.

\section{Thesauro}

Tesauro de Ciencias Sociales de la Unesco.

\section{Para citar este artículo}

Rovira-Rubio, R. A., \& Montoya-Castaño, M. A. (2021). Acción colectiva juvenil rural: resistencia y re-existencia en tiempos de posacuerdo (Riosucio, Colombia). Revista Latinoamericana de Ciencias Sociales, Niñez y Juventud, 19(1), 1-27.

https://dx.doi.org/10.11600/rlcsnj.19.1.4626

\section{Historial}

Recibido: 15.09.2020

Aceptado: 19.11.2020

Publicado: 18.12.2020

\section{Información artículo}

El artículo se desarrolló en el marco del proyecto de investigación Cartografías de la re-existencia juvenil en el presente colombiano: una Indagación para la territorialización de la paz. financiado por la Universidad de Manizales entre noviembre de 2017 y abril de 2020, contando con la colaboración del Programa de Jóvenes Investigadores Minciencias periodos 2018 y 2019. Área: otras ciencias sociales. Subárea: ciencias sociales interdisciplinarias. 


\title{
Rural collective youth action: resistance and re-existance in the post peace agreement (Riosucio, Colombia)
}

\author{
Abstract (analytical)
}

This article collects the findings of a research of the practices of resistance and re-existence present in the youth collective action deployed in Riosucio (Caldas), a rural area affected by the Colombian armed conflict. Its purpose was to analyze the ways in which collective action youth builds peaceful horizons in times of post-agreement. The research is qualitative ethnographic and incorporates visual ethnography; four youth collectives collaborated and also elaborated a documentary film material. The main conclusions are: the surge of these collectives as a wager to the multiple violences they recognize in their local and national territory, and the potential of art as means of resistance and re-existance for the construction of peace in the rural area, the historical epicenter of the war in the country.

Keywords

Rural youth, armed conflict, violence, resistance, esthetic, peace.

\section{Ação coletiva da juventude rural: Resistência e reexistência em Riosucio (Colômbia), em tempos de pós-acordo}

\section{Resumo (analítico)}

Este artigo reúne os resultados de uma investigação sobre as práticas de resistência e de reexistência presentes na ação coletiva juvenil implantada em Riosucio (Caldas), área rural afetada pelo conflito armado colombiano. Com o objetivo de analisar os modos de ação coletiva a juventude constrói horizontes de paz em tempos de pós-acordo. A pesquisa é qualitativa etnográfica e incorpora etnografia visual; Colaboraram quatro grupos de jovens com os quais também foi produzido um documentário. As principais conclusões são: a emergência dos grupos como aposta na violência que reconhecem no território local e nacional; e a potencialidade da arte como mecanismo de resistência e de reexistência para a construção da paz no campo, epicentro histórico da guerra no país.

\section{Palavras-chave}

Juventude rural, conflito armado, violência, resistência, estética, paz.

\section{Información autores}

[a] Psicóloga, Doctora en Psicología Social de la Universidad Autónoma de Barcelona (España). Docente investigadora del Centro de Estudios Avanzados en Niñez y Juventud de la Universidad de Manizales y Cinde. H5: 3. Correo electrónico: rrovira@umanizales.edu.co iD 0000-0003-1644-977X.

[b] Comunicadora Social y Periodista. Master en Educación y Desarrollo Humano del Centro de Estudios Avanzados en Niñez y Juventud de la Universidad de Manizales y Cinde, Joven Investigadora Ministerio de Ciencia, Tecnología e Innovación de Colombia (convocatorias 775 de 2017 y 812 de 2018). Correo electrónico: antoniamontoyacastano@gmail.com 


\section{Introducción}

\section{Riosucio, entre violencia y paz}

n el año 2017, tiempo en que inició la presente investigación, Colombia se encon-
traba en medio de un tránsito político y social que se desplegó luego de la firma de los acuerdos de paz entre las Fuerzas Armadas Revolucionarias de Colombia-Ejército del Pueblo (Farc-EP) y el Gobierno nacional, después de varias décadas de tensiones por la tenencia de la tierra, la violencia política y el conflicto armado (Molano-Bravo, 2015); contexto este que ha tensionado por décadas la posibilidad de participación y convivencia comunitaria armónica en diversos territorios del país especialmente rurales.

El proyecto de paz significó un horizonte al que se volcaron importantes esfuerzos institucionales. Sin embargo, a la fecha, ha sido entorpecido por intereses representados en instancias legislativas a través de presentación de proyectos de ley que buscan alterar los pilares fundamentales del punto uno del acuerdo: la reforma rural integral (proyecto de Ley oo3 de 2018); también por la continuidad de los asesinatos a líderes sociales, de los cuales entre septiembre de 2016 y febrero de 2020 han fallecido 565 (Botero \& Tavera, 2020); así como por los cientos de disidentes del proceso de reincorporación a la vida civil de las Farc-EP, que han decidido vincularse a las filas de otros grupos armados (Reuters, 2018).

Lo anterior evidencia las dificultades de la transición hacia la paz en Colombia, en tanto la violencia persiste en los territorios urbanos y rurales, así como en los estrados del poder institucional, condicionando la vida de los jóvenes del país y propiciando su muerte. Muestra de ello es la importante presencia de jóvenes en el registro de líderes asesinados (Somos Defensores, 2018) por adelantar procesos políticos y comunitarios en sus territorios, así como por la defensa y promoción de los puntos que integran el acuerdo de paz (Oficina del Alto Comisionado para la Paz, 2016).

A esto se suma una dificultad, como plantea Muñoz (2015): en Colombia se vivencia una realidad de muerte sistemática de jóvenes, la cual ha sido denominada «juvenicidio». 
Los jóvenes no solo mueren físicamente, sino también a través del atentado a la posibilidad de una vida digna, así como por medio de representaciones mediáticas y simbólicas que los refieren como delincuentes, desordenados e inadaptados; realidad compartida con otros países del continente, pero recrudecida por los marcos de conflicto prevalecientes en el país.

Riosucio (Caldas), ${ }^{1}$ el escenario de esta investigación. Es un municipio rural ubicado al noroccidente del departamento que ha sido epicentro de estas múltiples violencias. Históricamente allí se han dado temporadas de tensiones sociales: desde la violencia de los años cincuenta (Guzmán et al., 1962; Pécaut, 2001)², hasta la confrontación entre grupos armados en las décadas de los años ochenta y el 2000, principalmente entre frentes paramilitares (como el Cacique Pipintá) ${ }^{3}$, la guerrilla de las Farc-EP y la fuerza pública, quienes arremetieron contra la población a través de violencia política y crímenes de Estado (Appelbaum, 2007; Movimiento Nacional de Víctimas de Crímenes de Estado, 2018). Esto se refleja en las 12845 personas víctimas del conflicto armado en el territorio, particularmente de desplazamiento, actos terroristas, homicidios, masacres, secuestros, desapariciones, entre otros (Registro Único de Atención a Víctimas, 2020).

Aún en medio de este escenario, en el país se gestan apuestas colectivas juveniles de resistencia que posibilitan el encuentro entre las comunidades más allá de las dinámicas de la violencia. Estas iniciativas buscan construir territorios donde se logre el silenciamiento de las armas e imperen modos de construcción colectiva alrededor de la convivencia pacífica. Parte de las luchas indígenas, campesinas y juveniles tienen este fin; prácticas de relevancia en sus territorios donde aún se expone el cuerpo a la violencia

${ }_{1}^{1}$ Su fundación oscila entre los siglos XVIII y XIX (Henao-Carvajal, 2019). Se encuentra sobre la Cordillera Occidental de Colombia. Linda al norte con el departamento de Antioquia y al oeste con el departamento de Risaralda. Está compuesto por 64593 habitantes, de los cuales 7523 son jóvenes (Alcaldía de Riosucio, 2020). En el territorio se integran cuatro resguardos indígenas compuestos por población embera chamí: San Lorenzo, Nuestra Señora Candelaria de la Montaña, Escopetera y Pirza; Cañamomo y Lomaprieta (Departamento Administrativo Nacional de Estadística, 2018).

${ }^{2}$ La época de la Violencia surge con el episodio conocido como el Bogotazo (1948), produciéndose la muerte de aproximadamente 200 ooo personas en un país de 13 millones de habitantes.

${ }^{3}$ El grupo paramilitar Muerte a Secuestradores (MAS) actuó en el departamento en la década de los años ochenta. A principios del siglo XXI la organización se constituye en el Frente Cacique Pipintá, adscrito al Bloque Central Bolivar. Este Frente tenía influencia a lo largo del cañón del río Cauca, zona estratégica para el negocio del narcotráfico, porque allí se establecen conexiones entre Antioquia, el Eje Cafetero y el norte del Valle, como describe la Agencia de la ONU para los Refugiados (Acnur). 
por intentar generar escenarios de paz desde la acción colectiva (García, 2017; Muñoz \& Pineda, 2018; Ospina-Alvarado et al., 2018).

A su vez, el territorio se nutre de elementos sociales y culturales de la ruralidad colombiana como es su carácter indígena (Comisión Económica para América Latina \& Naciones Unidas, 2014) y cuenta con una significativa tradición folclórica reflejada en el Carnaval de Riosucio, que busca ser reconocido como patrimonio cultural de la humanidad (Ministerio de Tecnologías de la Información y Comunicaciones, 2019). Escenario en el que se despliegan diversos activismos sociales y juveniles que buscan otros modos de hacer la vida pese a la violencia, en medio de la riqueza de un paisaje que estimula la emergencia de una singularidad estética presente en diversas apuestas colectivas del municipio.

Esta investigación se pregunta: ¿cómo se configuran los procesos de construcción de paz a través de la acción colectiva juvenil en un territorio rural como Riosucio, Caldas? Estableciendo como objetivo analizar los modos en que la acción colectiva juvenil se desenvuelve a través de prácticas de resistencia y re-existencia en Riosucio, pese a las diversas violencias presentes en el territorio que atentan contra la vida de los jóvenes.

Para lo anterior, se establecieron como tareas investigativas: 1) identificar prácticas de acción colectiva, de resistencia y re-existencia, presentes en el territorio en medio de los efectos de la violencia; 2) reflexionar acerca de cómo se relacionan estas prácticas con procesos de construcción de paz.

En cuanto a antecedentes investigativos, son escasos los estudios en los últimos años que abordan la problemática. No obstante, se destaca el trabajo de Osorio-Pérez (2005) que da cuenta de la acción colectiva de jóvenes rurales en comunidades de los departamentos de Cundinamarca, Caquetá y Risaralda, estableciendo una caracterización de cinco aspectos relacionados entre sí que configuraran un difícil panorama para las y los jóvenes rurales colombianos: la concentración de la propiedad, la crisis del sector agropecuario, la agudización del empobrecimiento rural, los cultivos de uso ilícito y el conflicto armado. No obstante, los jóvenes «confrontan y asumen las condiciones adversas de sus entornos, reconfigurando cotidianamente sus propios territorios» (Osorio-Pérez, 2005, p. 127).

Esta investigación es un aporte a los estudios de juventud y a la elaboración de una literatura actualizada que dé cuenta de la acción colectiva juvenil rural en Colombia, ${ }^{4}$ en

\footnotetext{
${ }^{4}$ En motores de búsqueda como Clacso, Dialnet, Google Académico y la Revista Latinoamericana de Ciencias Sociales, Niñez y Juventud no se presentaron resultados de investigaciones en los últimos cinco años acerca de acción colectiva juvenil rural.
} 
tiempos del posacuerdo de paz y de la desmovilización de las Farc-EP. A continuación nos referiremos brevemente a los marcos analíticos de acción colectiva juvenil, resistencia y re-existencia.

\section{Marco analítico de comprensión}

La última década, atravesada por la globalización, el neoliberalismo y las nuevas tecnologías de la información y la comunicación, ha generado cambios en los modos en que se configuran los movimientos sociales. Estos no son necesariamente parte de algún partido o grupo social diferenciado (Feixa et al., 2002); se caracterizan por un accionar político encarnado en prácticas culturales y expresivas que se disputan los significados y el poder interpretativo de la realidad (Aguilar-Forero, 2015) y se organizan de modo reticular, flexible y no jerárquico (Seoane et al., 2006).

La acción colectiva juvenil (ACJ) se abre paso entre los movimientos sociales como medio para cuestionar y repoblar de significados el escenario público que constituye la cotidianidad política; esta es definida como un grupo de personas que se unen de manera intencionada y en defensa de intereses comunes a través de acciones concertadas en relación a causas que identifican colectivamente y se plantean como objetivo instaurar un «nuevo orden de vida» a diferentes escalas (Ibarra et al., 2018; Revilla, 1994). Así también, Aguilar-Forero (2015), entiende la ACJ como

toda forma de intervención colectiva, político-cultural, con protagonismo juvenil, mediada por la inconformidad, el descontento y la indignación como motores de un deseo de asociación y transformación. Es una lucha contra las condiciones de opresión, desigualdad, injusticia y dominación que en el proceso desata anomalías, genera interrupciones y recrea e impugna, desde lo cotidiano, lo naturalizado e instituido. (p. 5)

En este sentido, la acción colectiva juvenil como forma de participación es un mecanismo de vinculación y conexión con otros y otras, que conforma un nuevo sujeto político ante la habitual instrumentalización de la esfera pública, por lo que participar se acciona como un litigio por la palabra que instituye la política y no que deriva de esta (Reguillo, 2017); 5 teniendo presente que para muchos y muchas jóvenes organizados la participación ciudadana es una promesa no cumplida y una etiqueta que no refleja la

\footnotetext{
${ }^{5}$ Reguillo (2017) evoca la idea de política como litigio por la palabra de Rancière (2009), comprendiéndola como irrupción de los que no tienen parte.
} 
diversidad y especificidad de las demandas que se levantan desde las múltiples identidades que conviven en el mundo juvenil (Gamboa \& Pincheira, 2009).

De este modo, la ACJ se configura como una práctica de resistencia en tanto busca conducirse de otra manera, subvirtiendo el lugar que, desde los diversos roles sociales en el marco de la cultura colombiana, les son asignados a los y las jóvenes.

Por su parte, la resistencia juvenil se plantea como conductas que se rebelan frente a los procedimientos impuestos desde la práctica de conducir a los otros, rompiendo lazos de obediencia especialmente con el Estado (Foucault, 1977, 2006) y reemplazándolas por la ley de las propias necesidades situadas de las comunidades y de las exigencias juveniles.

La resistencia como contraconducta es una práctica de la que emergen nuevos modos de ser individuo y colectividad, y no necesariamente acciona buscando generar una única obra común pues es rizomática (Nancy, 2001). Las actuales acciones colectivas parecen responder más a lo que Aguilar-Forero (2015) llamara «comunica-acción», desde donde se generan formas creativas estético-expresivas mediante la comunicación, brindando lugar a la comunicación del común como testimonio de la narración del nosotros.

En la práctica artística el mundo afectivo se torna práctica política, acción y creación; de este modo, la resistencia resulta estética, siempre que encarna una forma particular de producirse desde lo estético y genera en su trama un arte de vivir diferente a lo disciplinado según las prescripciones sociales morales (Sánchez-Ávila, 2017). Que la acción sea estética e íntima no quiere decir que no pueda ser colectiva y política; según Jacques Rancière (2009) la estética sirve para pensar lo político. En este sentido, comprender el arte como práctica política implica que accione como mecanismo de resistencia que activa el juicio crítico y motiva la manifestación y representación de las realidades de las comunidades, activando la reconfiguración de la realidad desde lo sensible (ArcosPalma, 2009).

Pensar la acción colectiva juvenil como práctica estética política, nos pone ante el desafío de reflexionar sobre el arte de vivir desde un cuestionamiento crítico como práctica que conlleve a descolonizar las mentes y a deconstruir la colonialidad del ser (Castro-Gómez, 2002). Este planteamiento adquiere especial resonancia si nos situamos desde los territorios rurales, indígenas y afros de América Latina.

El cientista social y artista colombiano Albán (2009) invita a pensar la resistencia como tramar la vida en re-existencia, desde la cual se relaciona una contraconducta con el proceso de re-conocernos y auto-afirmarnos en nuestras particularidades, descentrando 
las lógicas establecidas por el proyecto hegemónico colonizador, buscando en las profundidades de las culturas nuestras formas organizativas, de producción, alimentarias, rituales y estéticas, con el objetivo de que estas permitan dignificar la vida y reinventarla continuamente.

Estas prácticas de acción colectiva (como prácticas de resistencia estético-política que abren paso a las posibilidades de las re-existencias) son prácticas constructoras de paz, en tanto que, al usar el potencial creativo del arte en iniciativas de procesos efectivos de resistencia ante situaciones de dolor y violencia, se puede influir significativamente en la imaginación del colectivo y generar transformaciones sociales descentralizadas de los agentes que continuamente detentan el poder, usualmente el Estado. Generando lo que el especialista en conflictos Jean Paul Lederach (2008) denomina "potencial de la imaginación moral», que permite que, aun cuando los individuos están en orillas opuestas, pueden encontrar maneras de vincularse para imaginar la paz.

\section{Método}

\section{Una apuesta etnográfica audiovisual}

La investigación fue de corte cualitativo (Sampieri et al., 2010), es decir, un ejercicio interpretativo e interesado por las formas en que el mundo social es comprendido, experimentado y producido. Se basó en la generación de datos tanto rigurosos como flexibles y sensibles del contexto en que se produjeron, sosteniéndose por métodos de análisis y explicación con los que se procuró la comprensión del contexto (Vasilachis, 2006).

El trabajo se realizó a través del método etnográfico (Guber, 2001) como técnica para construir datos descriptivos del contexto riosuceño, por medio de la etnografía visual (Ardèvol, 1998); esta es mecanismo para registrar y documentar la realidad sociocultural de los jóvenes en el territorio, a través de la foto fija, la entrevista en formato audiovisual, el registro de los paisajes sonoros y de la cotidianidad (Arango \& Pérez, 2007).

Entre 2017 y 2019 se realizaron 15 salidas de campo en el casco urbano y en zonas veredales del municipio de Riosucio. Comunidades como Sipirra, La Iberia y Las Estancias, espacios institucionales como el Centro de Capacitación Indígena Ingrumá, la Secretaría de Desarrollo Social y Comunitaria de la Alcaldía de Riosucio, así como escenarios abiertos y culturales como el Teatro Cuesta, el Encuentro de la Palabra (casa de la cultura), las 
plazas, los cafés y la misma intimidad de los hogares de los jóvenes y la comunidad riosuceña, fueron los lugares de indagación y conversación de esta investigación.

Se trabajó con cuatro colectivos juveniles conformados por participantes con edades entre los 17 y los 27 años: Colectivo Bulevar de las Artes, Colectivo Kurisía, Colectivo Segunda Escena y Colectivo CaminArte. El número de integrantes en los colectivos era relativo de acuerdo a las actividades organizadas desde los mismos; sin embargo, el promedio de la base organizativa era de cinco personas. El método para conectar con estos colectivos fue la estrategia de bola de nieve (Valles, 1997), por medio de una joven activista del territorio, que a su vez es parte de la comunidad académica como investigadora que nos posibilitó el compartir con los demás colectivos.

La investigación se trama entonces como un ejercicio comprometido, inmerso en la cotidianidad de los colectivos por lo cual estos se implicaron en calidad de colaboradores en la investigación, orientándonos a responder desde la interacción las siguientes preguntas: ¿cómo se habían gestado los colectivos?, ¿qué prácticas sociales realizaban?, y ¿cómo comprendían dichas prácticas y su relación con la resistencia y los procesos de construcción de paz en el territorio?

El proceso de recolección de datos se dio desde observación participante intensiva (Ameigeiras, 2006), de acompañamiento en múltiples actividades de los jóvenes, incorporando como instrumentos la elaboración de diarios de campo. Luego se gestaron conversatorios y talleres de discusión grupal acerca de los temas de investigación. Finalmente, se desarrollaron entrevistas individuales. Todos los procesos fueron grabados en formato sonoro, audiovisual y registrados fotográficamente (Hurtado, 200o).

De manera particular, para el ejercicio de las entrevistas se identificaron dos colaboradores por colectivo que fueron elegidos por el mismo grupo como voceros en las entrevistas (tabla 1); estas fueron insumos centrales para la elaboración del presente artículo y del cortometraje documental Riosucio Caldas: prácticas de resistencia estética juvenil. ${ }^{6}$

\footnotetext{
6 Se puede acceder a esta pieza documental a través del canal de Youtube Jóvenes, culturas y poderes: https:// www.youtube.com/watch?v=XkgWprqc3Ow
} 


\section{Tabla 1}

Colectivos juveniles participantes en el estudio y voceros entrevistas

\begin{tabular}{ll}
\multicolumn{1}{c}{ Colectivos } & \multicolumn{1}{c}{ Voces } \\
\hline Bulevar de las Artes & Adaluz y Margarita \\
Segunda escena & Adrián e Isabella \\
CaminArte & Pablo y David \\
Kurisía & Yamid y Juliana \\
\hline
\end{tabular}

El material obtenido se analizó con base en el análisis de contenido (Ruiz, 2006); de este modo se apuntó a acceder de manera sistemática a la descripción, clasificación y comprensión del mismo, para construir desde ello un texto donde los actores se vieran reflejados y reconstruidos desde el sentido que fija el objetivo de investigación. Para la organización y análisis del material se utilizaron las estrategias de delimitación y determinación (Ruiz, 2006), lo que permitió identificar contenidos claves por medio de la elaboración de una matriz, desde la cual posteriormente se argumentó la construcción de resultados escritos y audiovisuales.

El tratamiento de imágenes y contenido procuró conservar el mayor grado de fidelidad con las lecturas, sentidos y posturas de los jóvenes con quienes se trabajó; esto con el fin de cuidar los efectos de realidad (Bourdieu, 1997) que se pueden producir desde el manejo de los registros visuales, mostrando sus voces, sus contextos y evitando alterar su cotidianidad.

Finalmente, la base y el horizonte ético de esta investigación se centró en generar una relación entre el pensar, el hacer y el ser en la investigación en las ciencias sociales, como praxis política implicada, no extractivista; constructiva de un conocimiento variable y dialéctico que «nace de la ignorancia, en un esfuerzo por reducirla y llegar a ser más completo y exacto» (Fals-Borda, 1979/2009, p. 256); un reto que se tramita en la práctica (el terreno) y que procura, con gran esfuerzo, vincular el conocimiento y la acción en un deseo por comprender a través del esfuerzo existencial y la ampliación del espectro de la participación social en los procesos de investigación. 


\section{Resultados}

A continuación daremos cuenta de los principales hallazgos de la investigación en el encuentro con cada uno de los colectivos colaboradores.

\section{Colectivo Bulevar de las Artes: una salida de emergencia}

El Bulevar de las Artes es una apuesta cultural, principalmente de formación artística, que integra deporte y ciencia en un evento que se realiza cada año a lo largo de una semana (en el mes de diciembre) desde el 2011. Son varios escenarios culturales y deportivos los que componen la apuesta del Bulevar, reuniendo anualmente a más de 50 personas de todas las edades que aprenden de la mano de artistas y estudiantes universitarios de diferentes áreas del conocimiento que asumen su acción como un voluntariado.

El colectivo surge ante la conmoción de una de sus fundadoras, Adaluz Ortiz, poeta riosuceña quien, al estar en Cali participando de movimientos sociales estudiantiles (en una marcha de protesta contra la burocratización de la educación), presencia la explosión de un joven en medio de la movilización; ello la hace reflexionar acerca del uso de la violencia para reclamar derechos fundamentales, así como sobre los potenciales de paz que cada uno de nosotros y nosotras tiene. Adaluz relata su experiencia:

En una marcha un chico de la Universidad del Valle llevaba explosivos en su maleta. Mientras caminaba explotó la maleta con chico y todo. Fue un trauma para todo el mundo porque iban pacíficamente; nadie se esperó que uno de sus propios compañeros fuera armado. A partir de eso fue como... ¿qué está pasando?, ¿por qué debemos manifestarnos para pedir la libertad e igualdad con violencia y con dolor?, ¿por qué hacer sacrificios tan grandes para lograr cosas que ya nos pertenecen como la paz y la igualdad? (Comunicación personal)

Otra motivación que dio origen al Bulevar fue la crítica al ejercicio profesional de los jóvenes recién titulados de las universidades públicas, quienes contribuyen al orden mercantil laboral, al intercambiar su conocimiento por dinero. Las colaboradoras explican cómo el Bulevar se posiciona como una práctica de resistencia frente a esta dinámica:

La educación es pública mientras estás en la universidad, pero cuando sales de ella no eres público; tú necesitas tu sueldo, necesitas tu dinero, no vas a dar nada gratis. Estamos exigiendo educación pública, pero sabemos que no vamos a retribuir a la sociedad sin cobrar. 
Entonces pensamos: qué tal si creamos un evento en el cual exista un voluntariado de conocimiento con amigos que tengan proyectos universitarios o de investigación avanzados. (Comunicación personal)

Los talleristas y formadores, que vienen de distintas partes de Colombia, dan sus talleres y conversatorios de forma gratuita, en un voluntariado en el que muchas veces lo único que reciben es transporte y alimentación. Los niños y jóvenes que asisten también lo hacen sin ningún costo, varias veces acompañados por sus padres.

En esta misma línea el Bulevar no avala la violencia como forma de relación, pues la consideraron un juego más del mercado en el que no se debe caer:

Nosotros no vamos a responder con violencia porque eso es lo que quiere el sistema: que nosotros sigamos integrándonos al juego del mercader y al mercader le vale huevo venderle armas al paramilitar, al militar o al policía; le vale huevo venderle armas al padre de familia. Al mercader solo le importa vender. (Comunicación personal)

El colectivo se ha resistido a los mecenazgos, por lo que han buscado sus propios recursos para desarrollar las jornadas todos los años. En cuanto a las acciones que realiza el Bulevar, desde un inicio las artes han sido la resistencia explícita, su apuesta política para cesar el gran círculo vicioso que es la violencia:

No teníamos más expresión que una pintura o que una obra de teatro; no podíamos responder más a esa injusticia que de esta manera y no puedes esperar de nosotros otra cosa que no sea esto, porque esto para nosotros es resistir. Estamos cansados de vivir en el círculo vicioso de violencia. (Comunicación personal)

El arte se comprende para este colectivo como una herramienta fundamental para ampliar la imaginación, sensibilizar y permitir que emerjan pensamientos creativos sobre aquellos pensamientos miserables vinculados a las experiencias límite - como la pobreza y la guerra-. En palabras del colectivo:

¿Qué hace que una persona pueda elegir entre un camino u otro camino?, ¿qué hace que una persona deje de tener un pensamiento miserable? Pues ampliar los horizontes en la imaginación y eso era lo que proponíamos con Bulevar (...). El arte es el que nos sensibiliza; si somos seres sensibles no podemos no peleamos entre nosotros (...). Por ejemplo, en Riosucio se dio mucho la violencia política, entre liberales y conservadores; sin embargo, 
eventos como el Carnaval o como el Encuentro de la Palabra han transformado las cosas. (Comunicación personal)

El Bulevar de las Artes ha sido una salida de emergencia ante las violencias experimentadas por los niños, niñas y jóvenes en el desarrollo de sus vidas. El colectivo juvenil le apuesta a la construcción de individuos de paz, formando a niños, niñas y jóvenes; sembrando la inquietud por transformar la experiencia de una semana de diciembre en una vocación para la vida, que ya no solo se construye desde las artes, sino que también incluye las ciencias y el deporte desde el año 2018, creyendo que

eso es lo que haría un ser humano integral hacia la paz, que no solo se pueda volcar hacia el arte, sino que también explore su cuerpo. Si vibra o baila o corre va a encontrar complemento por todo lado. No todos somos artistas o científicos, puede haber un deportista. (Comunicación personal)

Finalmente, la misión del colectivo en 12 años se ha cumplido en tanto que «el Bulevar es una cosa que anda sola», de la que otros jóvenes se han hecho cargo a través del relevo generacional; «el Bulevar no se queda en una generación sino que se va transmitiendo por generaciones».

\section{Colectivo Segunda Escena: que la guerra se quede en el teatro}

Segunda Escena es un colectivo teatral fundado en el año 2011 mediante la iniciativa de Adrián González, un joven riosuceño que en el contexto del Carnaval de Riosucio se hace actor natural, pues en la dinámica de la festividad hay personas que se disfrazan, declaman y decretan, generando una afición por la cultura del arte teatral en jóvenes como Adrián. Este actor reconoce una experiencia crucial para la formación del grupo, que fue la que le abrió paso a una Segunda Escena de su vida:

En el año 2010 tuvimos un proceso con el maestro Misael Torres, del grupo Ensamblaje de Bogotá. Él pasó un proyecto con el Ministerio de Cultura y montó una obra para conmemorar el bicentenario de Colombia; se llamó El convite de los héroes. Con ese montaje nosotros hicimos diez funciones, recorrimos el Festival de Teatro de Manizales, fuimos al Iberoamericano, estuvimos en Huila. En esas funciones conocimos cómo era el ámbito del actor de teatro, dónde se movía y, cuando se termina ese proceso, nace Segunda Escena, con ese mismo impulso y esas ganas de seguir haciendo teatro. (Comunicación personal) 
El colectivo ensaya y monta en distintos escenarios de Riosucio, fundamentalmente en el Teatro Cuesta. Hasta la fecha Segunda Escena ha realizado el montaje de más de cinco obras con las que ha recorrido festivales nacionales e internacionales de teatro, dentro y fuera del país. Tiene siete actores en formación y un director de teatro especializado.

En estos casi diez años han dictado talleres en resguardos y comunidades indígenas de Riosucio y otras localidades del departamento de Caldas, establecimientos educativos de básica y media y universidades como la Universidad Nacional de Colombia. Además, han realizado procesos con población vulnerable, acercando el arte a estos lugares. Como plantea Isabella Escobar:

Con Segunda Escena hemos tenido la oportunidad de llegar a población vulnerable dentro de nuestro territorio o en otros contextos donde no es tan fácil que llegue el arte. Es lindo poder contribuir con ese tipo de cosas. (Comunicación personal)

El grupo se ha constituido en un proyecto de vida para sus integrantes y se busca profesionalizar, trascendiendo lo que inició con un hobby. Apuesta por fondos concursables gubernamentales. En la actualidad desarrollan un proyecto que ganaron a través de una convocatoria que financia su trabajo con comunidades indígenas:

Pasamos proyectos al Ministerio de Cultura y si nos los aprueban pues hay una fuente económica; y si no, pues esperamos la próxima convocatoria. En este momento nos ganamos la convocatoria de Comparte lo que Somos (Mincultura) y estamos realizando talleres con comunidades indígenas en los que apostamos a la reconstrucción de la memoria a través de la pedagogía teatral. (Comunicación personal)

Para los integrantes de Segunda Escena el teatro se configura como una práctica constructora de paz, dado que implica un proceso educativo que aleja de la guerra, por una parte, a través de talleres que se plantean como una práctica de resistencia que permite la identificación de presiones sociales y sus opciones de difracción, en consonancia con los planteamientos de Boal (2001) acerca de las posibilidades del teatro del oprimido. Así como también desde el montaje de obras por parte de la compañía, que comunican malestares sociales y, a partir de ello, inciden en las comunidades que son su público:

El teatro es una manera de mostrar una inconformidad; es una manera de educar. En esa educación hay que leer mucho y yo digo que si uno está en este camino de educación estamos más lejos de la guerra. La función de nosotros en el teatro sería representarla para 
que el público la vea y entienda desde otras perspectivas que estamos mal encaminados. (Comunicación personal)

La ficción del teatro permite recrear la guerra y verla en obra, posibilitando la educación acerca de sus efectos y con ello la reflexión para prevenir su reincidencia en la realidad:

Estamos hablando de que la guerra es una realidad y ojalá se quedara en el teatro; que se viera solo como obra, pero que la guerra no tocara los espectadores en la vida real. A mí me parece que el teatro en construcción de paz va muy de la mano en el sentido de que se está educando. Se tiene que educar para que cosas que suceden en la guerra se queden en el teatro y no pasen en la realidad. (Comunicación personal)

En palabras de Isabella, el hecho de mostrar la realidad a través del teatro posibilita la apropiación de la historia, porque «el arte sirve para el conocimiento, para la apropiación de la historia y más a través del teatro que es una herramienta tan linda para mostrar la realidad, ya sea con sus cosas feas o con sus cosas bonitas» (comunicación personal).

De este modo, los jóvenes de Segunda Escena practican el teatro como herramienta que incide en la formación de consciencia social individual y colectiva, para la transformación. Siguiendo a Bertolt Brecht (1948/2020), en el teatro se muestra que el mundo es contradictorio y transformable, desde el engañoso cambio de lo contradictorio a lo armónico, pudiéndose generar en el espectador el cuestionamiento para la transformación.

\section{Colectivo CaminArte: la paz desde adentro}

CaminArte es una propuesta de arte itinerante que surgió en el año 2014 motivada por la apuesta del Bulevar de las Artes. La idea del colectivo fue llevar la propuesta de formación del Bulevar a las zonas rurales del territorio de Riosucio, como una apuesta por resignificar aquellos espacios que han sido atravesados por la violencia y como una estrategia para descentralizar la oferta cultural. CaminArte - como el Bulevar- es un entramado de saberes de distintas índoles; estudiantes y profesionales de ciencias sociales y artes se reúnen e intercambian conocimiento con las comunidades:

Somos un grupo de jóvenes de diferentes disciplinas; en mi caso como estudiante de ciencia política. Así mismo, hay artistas plásticos, sociólogos, músicos, bailarines (entre otros perfiles), y cada uno desde sus conocimientos ha aportado al proceso para que se fortalezca en la parte logística y programática y en la parte social (...). Si bien Riosucio se caracteriza por ser un pueblo cultural y donde las manifestaciones artísticas han brillado, considera- 
mos que esa misma oferta cultural ha estado centralizada en la parte urbana del municipio. (Comunicación personal)

El colectivo no tiene agenda establecida, sino que se mantiene dispuesto. Cuando en el año coinciden algunos amigos, se toman los materiales de trabajo y se emprende la visita a las zonas rurales en las que se dan los talleres y se intercambian los saberes entre comunidad y talleristas. Pablo Cataño, uno de los fundadores del CaminArte, habla de la experiencia:

Algunos integrantes del Bulevar de las Artes pensamos viable la propuesta de llevar el Bulevar, pero a la zona rural del municipio. ¿Por qué a la zona rural? Pues porque esa zona ha sido un territorio tocado por los diferentes grupos al margen de la ley y las diferentes violencias, llamándolas en plural porque consideramos que no es una sola violencia la que ha tocado nuestro territorio, sino que han sido diferentes manifestaciones violentas por las que han tenido que pasar los pobladores. (Comunicación personal)

Este colectivo se caracteriza por tener una reflexividad crítica para pensar la ruralidad. A estos territorios se llevan talleres artísticos y culturales que se plantean como espacios de aprendizaje, donde unos aprenden de otros:

Nos pensamos el CaminArte como un espacio, no para llevar talleres de arte, de formación de danza, música, literatura, teatro, máscaras, tejido, etc., sino como una manera de dialogar; pues no nos volvemos depositarios de conocimiento, sino que dialogamos, nos comunicamos, aprendemos unos de otros. (Comunicación personal)

Los integrantes reconocen la historia de violencia de guerra que ha atravesado el municipio, proponiendo CaminArte como una apuesta juvenil constructora de paz:

En un pueblo tan enemistado, donde nuestros cuatro resguardos indígenas han sido considerados víctimas colectivas de un conflicto armado que ha acallado sus luchas, que los ha estigmatizado, consideramos que cuando entre los jóvenes nos reconocemos y trabajamos juntos, hay paz, se hace la paz. (Comunicación personal)

Estos procesos se proponen como constructores de paz porque acercan nuevas herramientas a los niños, niñas y jóvenes de los territorios, sustituyendo la cercanía de los jóvenes a la ilegalidad, por la cercanía al arte: 
CaminArte es un constructor de paz no solamente como propuesta social de intervención, sino porque en su quehacer está el arte y el arte indudablemente es un transformador de vidas; porque es preferible cuando un chico tiene un pincel en la mano y no tiene un puñal o un arma. Y es definitivamente lo que nos hemos propuesto: que se conozcan otras opciones, que se tenga otra posibilidad de vivir la realidad en la que estamos. (Comunicación personal)

David Grisales, artista plástico y también integrante del colectivo, plantea una idea frente al arte como pedagogía del ser y como experiencia de paz:

Para mí el arte en sí es una experiencia de paz; desde uno sentarse a construir algo con sus manos y tener el placer de verlo terminado y construido, eso genera paz en uno. Los momentos de contemplación generan tranquilidad, dispersión; generan un pensamiento distinto ligado al cotidiano alrededor de los medios y la violencia, en el país y en el mundo. (Comunicación personal)

Considera que la formación en artes dista de la educación tradicional; pues se constituye como una actividad para reconocer capacidades autónomas y formar personas resilientes:

El arte nos enseña algo que en la educación tradicional no nos enseñan y es a equivocarnos: tenemos que experimentar y hacer, y probar, y tocar, y sentir para poder ir reconociendo nuestras capacidades y reconociéndonos nosotros mismos. Eso es lo que necesitamos: no únicamente un país en paz, sino personas que tengan la paz adentro. (Comunicación personal)

El artista finaliza diciendo:

El arte y la cultura dan una voz que no se da con la palabra, sino con el hacer de nuestras manos, de nuestra boca, de nuestro cuerpo, a través de otra sensibilidad. A mí, por ejemplo, la alfarería me acercó a la paciencia; antes era muy impaciente para hacer las cosas y, a través de la alfarería, supe que cada cosa tiene su tiempo, que cada momento es necesario experimentarlo; me dio herramientas para adquirir una técnica propia y para poder enseñarla, y dar las pautas a la gente para que tenga sus propios caminos, y para que construya su propio saber. Creo que eso es lo fundamental para construir individuos y sociedades. (Comunicación personal) 


\section{Colectivo Kurisía: pervivir en el tiempo}

Kurisía es una palabra en lengua embera que traduce pensamiento. Este es un proyecto conformado por cinco jóvenes de comunidades indígenas caminantes de la medicina tradicional, quienes crearon el grupo en el año 2018 a través de la reflexión acerca del proceso de aculturación que afecta las tradiciones, la cosmovisión y la cosmogonía de los pueblos indígenas. El joven taita Yamid González cuenta sobre el origen del colectivo:

Notamos que hay mucha aculturación; adopción de otras culturas de afuera que lamentablemente perjudican mucho la cultura, las tradiciones, la cosmovisión y la cosmogonía de nuestros pueblos indígenas. Entonces de allí sale la necesidad de que esta sanación, no puede ser solo personal, sino colectiva para las personas de las ciudades y los jóvenes que han perdido sus caminos y sus raíces. (Comunicación personal)

Hay una relación inexorable entre la espiritualidad y la práctica de acción colectiva de Kurisía; una comprensión crítica de la realidad que pasa por los marcos de lo espiritual. Incluso los efectos de la industria del entretenimiento son considerados una enfermedad del espíritu que puede ser canalizada a través de medicinas como la música, la danza y las medicinas ancestrales:

En esos procesos de aculturación vienen muchas problemáticas y enfermedades; por ejemplo, la música, el reggaetón, la música popular, en fin, cantidad de músicas que lo que hacen es enfermar el pensamiento de las personas, siempre incitando a consumir licor, drogas, sexo. Todo eso lo que hace es enfermar el pensamiento y esto hace que las personas se olviden de lo que realmente es importante, que es vivir en armonía y conexión con la naturaleza. (Comunicación personal)

La principal herramienta de la que se vale el colectivo para compartir su conocimiento y ayudar a sanar es la músico-medicina:

La música medicinal, la música de conciencia. Sabemos que así como las personas adoptan esas otras culturas de la música, la música medicinal es mucho más fuerte porque ella trae unos mensajes y unas vibraciones que, si nos sabemos conectar con ella, vamos sanando nuestro cuerpo, nuestro espíritu y nuestros pensamientos. (Comunicación personal)

Aun cuando hay escepticismo por parte de posturas occidentalizadas que cuestionan y rotulan con severidad las prácticas ancestrales, Yamid habla de la actividad del colectivo como un proceso de construcción de paz, el cual se basa en la recuperación de memorias 
de los antepasados, desde las cuales se activa el compartir del legado cultural del pueblo: «es importante compartir las enseñanzas que he recibido de mis abuelos y los mayores porque todo esto genera un impacto para generar equilibrio en la naturaleza y en la armonía de nuestros pueblos» (Comunicación personal).

El colectivo reconoce una influencia del sistema respecto al malestar de la vida de los individuos:

En todo el mundo hay unos sistemas impuestos por algunos seres que lo único que buscan es el poder y el control de la humanidad poniéndoles una venda en los ojos. Hay muchos sistemas: la política, las religiones, la música, la medicina occidental. Nosotros, por ser humanos, somos seres perfectos, y estos sistemas enseñan que el hombre es incompleto, inacabado y la espiritualidad muestra lo contrario (...); tenemos potencial para cambiar y ser mejores. (Comunicación personal)

El propósito del colectivo es tramitar la sanación individual y colectiva de las comunidades, fundamentalmente de los jóvenes. El horizonte de esta sanación es generar conciencia del vínculo con la tierra y la vida en armonía de los seres humanos; entre - y conellos mismos y la naturaleza. Según Juliana Franco con lo que hacen le arrebatan el concepto de lo político al ágora administrativa y gubernamental y se lo entregan a las personas en su construcción de sentidos:

Es inevitable generar procesos políticos, viendo la política no desde la óptica de promesas de gestión, sino viendo la política como una estrategia para construir tejido social; una estrategia para generar desarrollo social en la parte espiritual de cada persona. (Comunicación personal)

Otra idea - la de pervivir - aparece en el discurso de Kurisía. Esta vez Juliana explica cómo la resistencia no es un acto restringido a lo físico, sino que es un modo, una manera de acontecer en el tiempo que permite contener los sentidos en torno a asuntos esenciales como la identidad y la espiritualidad:

Nosotros resistimos a través del tiempo, porque a nosotros como población indígena, como jóvenes, el sistema nos ha querido imponer, nos ha querido cambiar muchas formas de pensar. Cuando hablamos de resistencia no hablamos de resistencia física nada más, hablamos de resistencia en pensamiento y en espíritu porque eso es lo que nos lleva de una u otra forma a pervivir en el tiempo con nuestras creencias, con nuestros estilos de vida 
originales, lo que nos permite tener el criterio y la fortaleza para evitar adaptarnos a otros estilos de vida que pueden perjudicar nuestra espiritualidad. (Comunicación personal)

El trabajo comunitario de Kurisía se reconoce como una herramienta que fortalece la identidad de las comunidades, desde el trabajo conjunto y el apoyo mutuo:

El colectivo ha fortalecido la identidad por los procesos comunitarios; ha ayudado a identificar y a determinar que, con el trabajo en equipo, lo que nosotros llamamos «mingas», por ejemplo, se pueden hacer cosas para beneficio de todos. Eso es lo que yo resalto de ese proceso juvenil. (Comunicación personal)

Finalmente, Kurisía reconoce el trabajo mancomunado de los distintos colectivos como un accionar que genera un tejido de

redes de contacto donde en cada sector. En cada zona de nuestro municipio se están llevan a cabo procesos distintos, pero todos con el mismo propósito: que la población, empezando por la (...) juvenil, cada vez sea más sensible y más humana para generar un ambiente de vida más agradable, un ambiente de armonía, tranquilidad y paz. (Comunicación personal)

\section{Discusión}

\section{Abonos para la construcción de paz}

A lo largo de este trabajo se dieron elementos para llegar a aproximaciones comprensivas acerca de la configuración de horizontes de paz constituidos por las prácticas de resistencia y de re-existencia de la acción colectiva juvenil. Se presentaron cuatro experiencias: Bulevar de las Artes, cuyo gesto de rebeldía es la cooperación, la radicalidad respecto a la no violencia y la formación en artes, ciencia y deportes; CaminArte, que descentraliza de forma crítica la oferta cultural emergente de sus mismas iniciativas; Segunda Escena, que ha hecho de su experiencia un proyecto de vida en concordancia con su apuesta política e ideológica; y Kurisía, que cuestiona la globalización y la industria del entretenimiento en sus efectos de ruptura de profundos valores y prácticas culturales indígenas. Todas estas son prácticas que se constituyen como ejercicio colectivo de resistencia y re-existencia, en tanto que resisten a múltiples violencias de carácter directo y estructural (Galtung, 2003), así como re-significan a través del arte y las prácticas comunitarias la cultura del conflicto inscrita en los territorios urbanos y rurales de Colombia. 
Acerca del cómo resisten, se da cuenta que una de las características fundamentales que comparten los colectivos es el deseo de accionar procesos ante la consciencia de las violencias que atraviesan su territorio, principalmente aquellas vinculadas al conflicto armado y a las producidas por las economías mercantilistas; ello motiva a los jóvenes a reunirse en función de generar espacios donde se puedan dar modos de convivencia pacífica y afectiva, así como crítica y reflexiva.

Los colectivos gestionan también procesos conjuntos como un movimiento juvenil en el territorio (Reguillo, 20oo); este convoca a la comunidad al espacio público, en función de prácticas para la construcción de horizontes de paz, contribuyendo a potenciar las capacidades presentes en los niños, niñas y jóvenes del territorio. Así, despliegan una red de comunica-acción (Aguilar-Forero, 2015) que es rizomática y en la que, como hemos enunciado de la mano de Nancy (2001), no pretende una única obra.

En cuanto a sus modos de organización interna, estos son polifacéticos y no jerárquicos, incluso en medio de la diversidad de edades y de niveles de formación. En relación a sus recursos económicos, en su mayoría los integrantes de los colectivos no reciben retribución monetaria y ejercen una labor que en palabras de Adaluz, del Bulevar de las Artes, es un voluntariado social artístico, que se resiste a los mecenazgos y clientelismos, y cuyo propósito es el compartir libre, pacífico y comunitario.

Así mismo, la acción colectiva juvenil plantea en su hacer una variación de la relación con el tiempo; temporalidades que, como planteó Amador-Baquiro (2016), no coinciden con las coordenadas orientadas desde las instituciones. Lo anterior se hace posible desde diversas experiencias estéticas que permiten conectar con un tiempo diferente, en lo que Pendzik (2015) plantea refiriéndose al teatro con la expresión ficcionada de una realidad dentro de otra (pintar, actuar, modelar, etc.), como prácticas performativas. Prácticas que agujerean la realidad normada del tiempo lineal y acelerado, donde las obras como productos culturales adquieren una importancia que no concuerda con el valor de mercado, pues no son actividades productoras de bienes de consumo.

Este tiempo estético permite conocimiento y desarrollo personal, así como un medio para tramitar el dolor del malestar social. Acerca del desarrollo personal, se plantea que el arte brinda herramientas para sensibilizar, cultivando la paciencia y la dedicación que requiere una obra, accionando lo que, según el colectivo CaminArte, se configura como una alquimia del autoreconocimiento; un camino de frustraciones, dolores, aprendizajes e identificación de capacidades, que resultan del proceso de creación y sanación. 
Acerca de la tramitación del malestar social, el arte se reconoce como una herramienta que, a través del artilugio de la representación, permite educar para que la guerra, la violencia y la desigualdad se queden en la ficción (como, por ejemplo, del teatro) y no se incorporen marcos de acción en la vida cotidiana como planteó el colectivo Segunda Escena.

Resulta particularmente interesante que los colectivos juveniles, lejos de tramitar un olvido de las violencias o un dejar atrás, deciden seguir sintiendo las marcas de su tiempo, no solo como disconformidad o descontento (Aguilar-Forero, 2015), sino que directamente identifican el dolor de las violencias necesarias de abordar; y, desde ellas, abren el encuentro con otros pares con los que comparten y se reconocen mediante procesos creativos, como acciones que les permiten develar una parte del quienes son ante otros, situar el dolor en una obra para cultivar y elaborar el reconocimiento de un malestar a través de sanar lo que llaman «la paz desde adentro».

Esto coincidente con las características de la acción colectiva actual planteada por López (2015): primero, como tiempo en que se evidencian los procesos de homogenización de las actuales relaciones, especialmente con el capital y las permanentes prácticas de muerte que acredita el gobierno cómplice a la ilegalidad; segundo, que los colectivos se posicionan desde una fracción de la realidad del por qué luchar; y, tercero, propenden a la resistencia a este presente.

Si bien todos los colectivos dan cuenta de procesos de resignificación de la realidad, es el colectivo Kurisía donde la resistencia se devela con más fuerza como práctica de reexistencia (Albán, 2009). Kurisía plantea su trabajo como una apuesta por sanar a través de las medicinas tradicionales, especialmente a través de la musicoterapia. Este es un trabajo estético que es evocación ancestral y recuperación de las memorias; un acto por decolonizar el ser, lo que despliega la potencia de lo propio de las comunidades embera y plantea otro modo de hacer vida. Práctica dada desde un colectivo principalmente embera Chamí, que permite identificar también la construcción de significados específicos del ser joven indígena, presentando modos de acción colectiva que tienen como recurso la comunicación intergeneracional, atendiendo a sus tradiciones políticas y culturales (Oliveira, 2020).

El relacionamiento a la construcción de horizontes de paz se comprende desde: 1) la construcción de valores en torno a la no violencia; 2) la formación en disciplinas y artes; 3) la motivación al cuestionamiento y la reflexión crítica frente a las políticas de gobierno y la acción del Estado; y, 4) el cuestionamiento al sistema social y cultural que se configura en medio de la globalización y el consumismo. 
La acción colectiva juvenil encarna en sus posicionamientos y movilizaciones la construcción de una paz desde abajo, emprendida primeramente con niños, niñas y jóvenes, pero también con las comunidades en su conjunto del territorio; lo anterior, de forma situada, en medio de experiencias colaborativas, autogestionadas y con la claridad que sus acciones son respuestas a una lectura crítica de país, de territorio, de historia y de actualidad. De este modo, la construcción de paz deviene de potenciar la imaginación moral, que se sintetiza para los colectivos desde prácticas estéticas que cultivan la conciencia crítica acerca de las memorias del territorio, que recogen los dolores comunes y generan otros puntos de encuentro para tramar vidas juntos.

Por último, esta investigación aporta a la comprensión de la figura del joven rural como un individuo que trasciende en su actividad política y sociocultural, la mirada funcional y comúnmente adultocéntrica que lo proyecta como una pieza más del mercado de trabajo, donde

pese a las múltiples condiciones adversas, o quizá a la par con éstas, jóvenes en diversas zonas rurales reinventan, transgreden y resisten la negación o indiferencia social de que son objeto, y siguen ensayando alternativas individuales y colectivas que les permitan un mayor bienestar. (Osorio-Pérez, 2005, p. 130)

Así, se proponen reflexiones en torno a cómo la acción colectiva juvenil rural representa un potencial para la construcción de paz de manera situada, a través de prácticas estéticas y políticas generativas de convivencia y reflexividad que se posicionan incluso frente a la actualización de la violencia en tiempos del posarcuerdo. Poniendo el acento en los jóvenes como quienes problematizan las realidades sociales, políticas y económicas, potenciando la idea de transformación de la sociedad, superando la visión patologizante hacia los jóvenes, en relación con el fracaso o el éxito en el afrontamiento de las problemáticas sociales que genera la guerra (Parra-Valencia et al., 2018).

Sin embargo, como proyección, creemos que se hace necesario indagar en otros territorios nacionales para generar mayor conocimiento acerca de la acción colectiva juvenil rural en Colombia, sus características, necesidades y fortalezas; ello en los lugares más afectados por la guerra, para aportar a la comprensión tanto de las actuales juventudes rurales como también a los modos de la actual acción colectiva juvenil en Latino América. 


\section{Agradecimientos}

Agradecemos a los y las jóvenes de los colectivos colaboradores de Riosucio (Caldas) por su palabra y acción que permite una mayor comprensión de la acción colectiva juvenil rural en el presente; a la Universidad de Manizales por posibilitar el proyecto y al Ministerio de Ciencia, Tecnología e Innovación por la beca Joven Investigador.

\section{Referencias}

Aguilar-Forero, N. (2015). La reinvención de la emancipación social: aportes para pensar la acción colectiva juvenil. Escrituras emergentes de las juventudes latinoamericanas. Gedisa. Albán, A. (2009). Pedagogías de la re-existencia: artistas indígenas y afrocolombianos. Signo. Alcaldía de Riosucio. (2020). Mi municipio. http://bit.ly/3afO1dm

Amador-Baquiro, J. C. (2016). Jóvenes, temporalidades y narrativas visuales en el conflicto armado colombiano. Revista Latinoamericana de Ciencias Sociales, Niñez y Juventud, $14(2), 1313-1329$.

Ameigeiras, A. (2006). El abordaje etnográfico en la investigación social. En I. Vasilachis (Coord.), Estrategias de investigación cualitativa (pp. 107-151). Gedisa.

Appelbaum, N. (2007). Dos plazas y una nación: raza y colonización en Riosucio, Caldas, 1846-1948. Instituto Colombiano de Antropología e Historia.

Arango, G., \& Pérez, C. (2007). Atrapar lo invisible: etnografía audiovisual y ficción. Anagramas, 6(12), 129-140.

Arcos-Palma, R. J. (2009). La estética y su dimensión política según Jacques Rancière. Nómadas, (31), 139-155.

Ardèvol, E. (1998). Por una antropología de la mirada: etnografía, representación y construcción de datos audiovisuales. Revista de Dialectología y Tradiciones Populares, 53(2), 218-240. https://doi.org/10.3989/rdtp.1998.v53.12.396

Boal, A. (2001) Teatro del oprimido: juegos para actores y no actores. Alba.

Botero, D., \& Tavera, E. (2020, 26 de febrero). Desde la firma del Acuerdo de Paz asesinaron a 565 líderes sociales. Hacemos memoria. https://bit.ly/2IR26Th

Bourdieu, P. (1997). Sobre la televisión. Anagrama.

Brecht, B. (2020). Pequeño organón para el teatro. Universidad Nacional Autónoma de México. (Obra original publicada en 1948). 
Castro-Gómez, S. (2002). Ciencias sociales, violencia epistémica y el problema de la «invención del otro». Clacso.

Comisión Económica para América Latina \& Naciones Unidas. (2014). Los pueblos indígenas en América Latina: avances en el último decenio y retos pendientes para la garantía de sus derechos. https://bit.ly/2KxVHgb

Departamento Administrativo Nacional de Estadística. (2018). Censo nacional de población y vivienda, Riosucio, Caldas.

Fals-Borda, O. (2009). Cómo investigar la realidad para transformarla. Clacso. (Obra original publicada en 1979).

Feixa, C., Costa, C., \& Saura, J. (2002). Movimientos juveniles: de la globalización a la antiglobalización. Ariel Social.

Foucault, M. (1977). Historia de la sexualidad: la voluntad de saber. Siglo XXI.

Foucault, M. (2006). Seguridad, territorio, población. Curso en el Collegge de France (1977-1978). Fondo de Cultura Económica.

Galtung, J. (2003). Paz por medios pacíficos: paz y conflicto, desarrollo y civilización. Gernika Gogoratuz.

Gamboa, A., \& Pincheira, I. (2009). Organizaciones juveniles en Santiago de Chile: invisibles_ subterráneas. LOM.

García, C, (2017). Re-existencias juveniles en Colombia: itinerancias desde la construcción de paz y la educación popular. Editorial Zapata.

Guber, R. (2001). La etnografía: método, campo y reflexividad. Norma.

Guzmán, C. G., Umaña, L. E., \& Fals-Borda, O. (1962). La violencia en Colombia: monografías sociológicas. Universidad Nacional de Colombia.

Henao-Carvajal, O. (2019). Historia de dos plazas. Editorial Andina.

Hurtado, J. (200o). Metodología de la investigación holística. Ediciones Colombia.

Ibarra, M., Rodríguez, A., Cuesta, I., \& Luna, Y. (2018). Mujeres en movimiento y repertorios de acción en Colombia. Universidad del Valle.

Lederach, J. P. (2008). La imaginación moral: el arte y el alma de construir la paz. Norma.

López, S. (2015). Breve tratado para atacar la realidad. Tinta Limón.

Ministerio de Tecnologías de la Información y Comunicaciones. (2019). Carnaval de Riosucio se inmortaliza como patrimonio cultural de la humanidad con estampilla del Mintic.

Molano-Bravo, A. (2015). Fragmentos de la historia del conflicto armado (1920-2010). Centro de Memoria Histórica.

Movimiento Nacional de Víctimas de Crímenes de Estado. (2018). Caldas en contexto. https://movimientodevictimas.org/caldas/ 
Muñoz, G. (2015). Juvenicidio en Colombia: crímenes de Estado y prácticas socialmente aceptables. En J. Valenzuela (Coord.), Juvenicidio: Ayotzinampa y las vidas precarias en América Latina y España (pp. 131-165). NED.

Muñoz, G., \& Pineda, J. (2018). Robándole tiempo a la muerte: inxilio, acción colectiva y reexistencia. Editorial Zapata.

Nancy, J. L. (2001). La comunidad desobrada. Arena Libros.

Oficina del Alto Comisionado para la Paz. (2016). Acuerdo final para la terminación del conflicto y la construcción de una paz estable y duradera.

Oliveira, A. C. (2020). Juventudes, Estado e Povos Indígenas no Brasil do Século XXI. Revista Latinoamericana de Ciencias Sociales, Niñez y Juventud, 18(1), 1-25. https:// doi.org/10.11600/1692715x.18105

Osorio-Pérez, F. (2005). Jóvenes rurales y acción colectiva en Colombia. Nómadas, (23), $122-131$.

Ospina-Alvarado, M. C., Rovira-Rubio, R. A., \& Melenge, J. (2018). Sentidos y prácticas de jóvenes investigadores e investigadoras, semillas de paz. Editorial Zapata.

Parra-Valencia, L., Aponte-Muñoz, A. C., \& Dueñas-Manrique, M. M. (2018). Jóvenes, grupo y arte: las personas jóvenes y el arte re-unidos. Revista Latinoamericana de Ciencias Sociales, Niñez y Juventud, 16(2), 853-865. https://doi.org/fnxs

Pécaut, D. (2001). Orden y violencia: evolución socio-política de Colombia entre 1930 y 1953. Norma.

Pendzik, S. (2015). La realidad dramática y sus implicaciones terapéuticas. Investigación Teatral. Revista de Artes Escénicas y Performatividad, 4(7-8).

Rancière, J. (2009). La dimensión estética: estética, política, conocimiento. Ciencia Política, 10(19), 21-43. https://doi.org/10.15446/cp.v10n19.52370

Registro Único de Atención a Víctimas. (2020). Unidad para la atención y la reparación integral a las víctimas. http://bit.ly/3ase 815

Reguillo, R. (2000). Estrategias de desencanto emergencia de culturas juveniles. Norma. Reguillo, R. (2017). Paisajes insurrectos: jóvenes, redes y revueltas en el otoño civilizatorio. NED. Reuters. (2018). Suben a 1200 rebeldes de Farc que se apartaron de acuerdo de paz en Colombia. https://lta.reuters.com/articulo/

Revilla, M. (1994). El concepto de movimiento social: acción, identidad y sentido. Zona Abierta.

Ruiz, A. (2006). Texto, testimonio y metatexto: el análisis de contenido en la investigación en educación. En A. Torres \& A. Jiménez (Comp.), La práctica investigativa en ciencias sociales (pp. 44-59). Universidad Nacional de Colombia. 
Sampieri, R., Fernández, C., \& Baptista, M. (2010). Metodología de la investigación. McGrawHill.

Sánchez-Ávila, F. (2017). El placer del otro y la estética de la existencia. Dorsal. Revista de Estudios Foucaultianos, (2), 81-109.

Seoane, J., Taddei, E., \& Algranati, C. (2006). Las nuevas configuraciones de los movimientos populares en América Latina: política y movimientos sociales en un mundo hegemónico. Clacso.

Somos Defensores. (2018). Más allá de las cifras: segunda parte. https://bit.ly/37mIcJu

Valles, M. S. (1997). Técnicas cualitativas de investigación social. Síntesis.

Vasilachis, I. (Coord.) (2006). Estrategias de investigación cualitativa. Gedisa. 